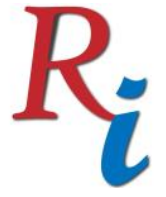

Asia Proceedings of Social Sciences

(APSS)

www.readersinsight.net/APSS

\title{
THE PREDICTIVE EFFECTS OF PROTECTION MOTIVATION THEORY ON ADAPTIVE BEHAVIOUR TOWARDS URBAN AIR QUALITY
}

\section{Syazwani Sahrir*}

Department of Environmental Management, Faculty of Environmental Studies Universiti Putra Malaysia

Malaysia

syazwani.sahrir@gmail.com

\section{Ahmad Makmom Abdullah}

Department of Environmental Sciences, Faculty of Environmental Studies

Universiti Putra Malaysia

Malaysia

amakmom@upm.edu.my

\section{Zakiah Ponrahono}

Department of Environmental Management, Faculty of Environmental Studies Universiti Putra Malaysia

Malaysia

zakh@upm.edu.my

\section{Amir Hamzah Sharaai}

Department of Environmental Management, Faculty of Environmental Studies Universiti Putra Malaysia

Malaysia

amirsharaai@upm.edu.my

*Corresponding author's Email: syazwani.sahrir@gmail.com 


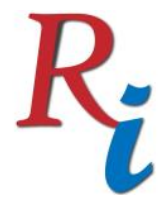

Asia Proceedings of Social Sciences

(APSS)

www.readersinsight.net/APSS

\section{A b s tract}

In urban areas, the rigid division of residential, commercial, employment and recreational areas forms a reliance on road transport, which leads to high levels of emission that gradually affects the quality of the urban environment. We establish Protection Motivation Theory (PMT) as a framework for explaining adaptive behavioural responses among urban communities in Malaysia. Participants ( $\mathrm{N}=450)$ answered to face-to-face questionnaire survey, and the results specify establishment for the proposed model, with perceived vulnerability $(\mathrm{H} 1) \quad(\beta=0.246, \mathrm{t}$ $=4.534, \mathrm{P}=0.000)$ and and self-efficacy $(\mathrm{H} 3)(\beta=0.510, \mathrm{t}=9.653, \mathrm{P}=0.000)$ positively predicting adaptive behaviour on urban air pollution. The results presented that these structures were able to predict $47 \%$ of the variance of adaptive behaviour. The study establishes a significant contribution to the literature by contributing an indication of PMT as an ideal framework for adaptive behavioural responses on urban air pollution.

\section{Research High I ight s}

Air quality is the key aspect of city life and urban metabolism to sustain the cycle process of urban growth and development. The severity of air emission in urban areas has been acknowledged for ages, but then the behaviour of the community to them is uncertain. Through a better understanding of individual behaviour responses towards poor-quality air, the negative impacts of air pollution can be reduced. We claim that PMT is an applicable framework for explaining the adaptive behavioural responses of the public. Moreover, a panel of structural equation modelling PLS-SEM is applied to capture the causal effect of current adaptative behavioural responses to air pollution and the factors driving these responses among urban Malaysian residents. The study presented that even though there was a correlation between all the constructs of the PMT, only perceived vulnerability and self - efficacy were able to predict the adaptive behaviour in this local context. 


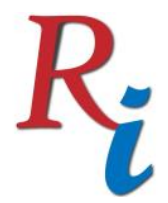

Asia Proceedings of Social Sciences

(APSS)

www.readersinsight.net/APSS

\section{Graphical A bstract}

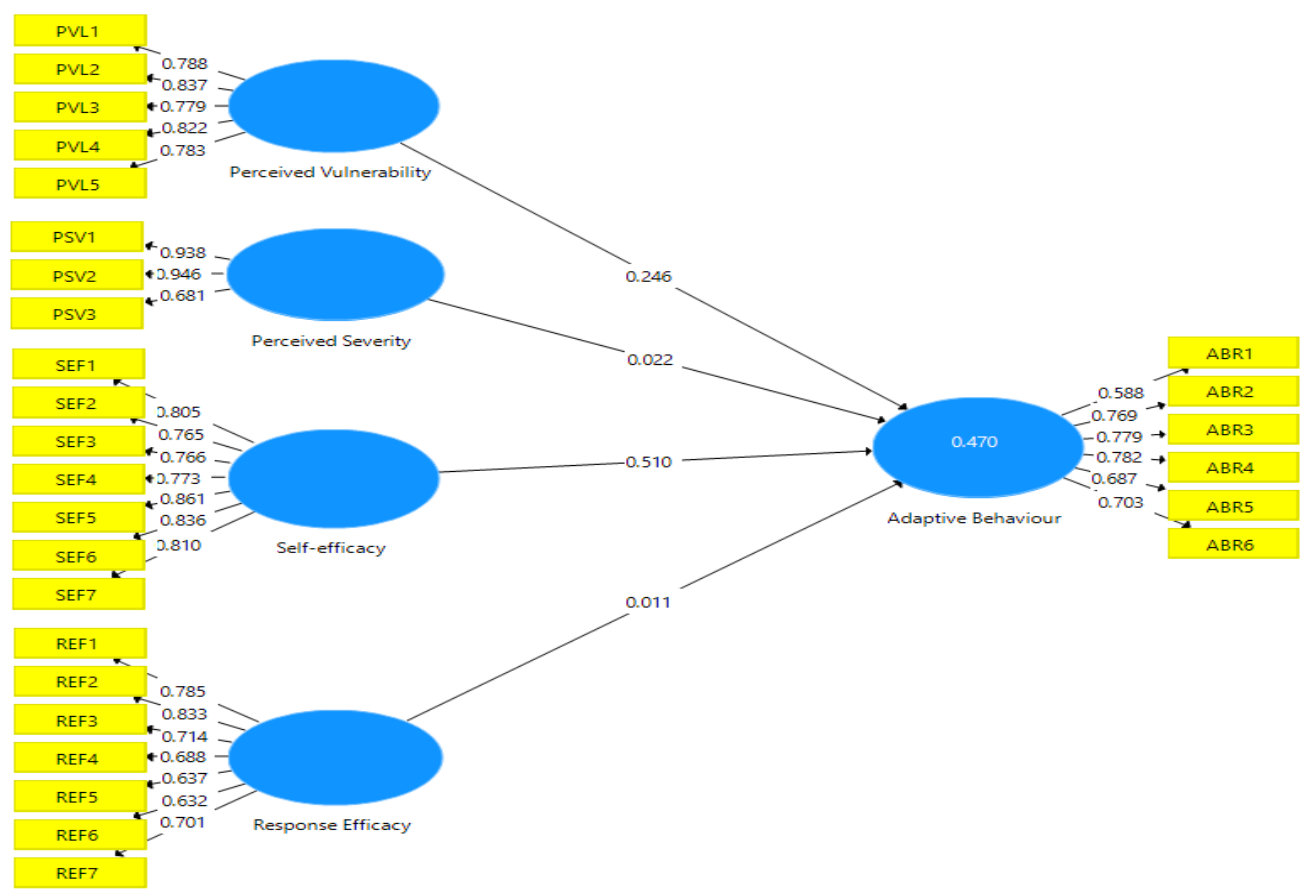

Analysis of the SmartPLS route model

\section{Research Objectives}

The aim of this study was to examine the predictive power of the Protection Motivation Theory as a framework in explaining adaptation towards urban air pollution. PMT (Rogers, 1975) is an ideal illustration of a framework that can be tested by researchers for unfolding adaptive behavioural responses on air quality. This theory is used to explain behaviors or intentions of risk reduction in carrying out protective behaviors. In summary, our proposed model's four main components are perceptions of vulnerability, severity, self-efficacy, and response efficacy. Numerous studies show that it is not only important to address the spatiotemporal variation and air pollutant trends, but also to maintain certain group behavioral characteristics themselves (Ban, Zhou, Zhang, Anderson, \& Li, 2017; Giles et al., 2011; Laumbach, Meng, \& Kipen, 2015). In addition, people's behaviour and action towards preventive measures depend on the way they perceive environmental stimuli, thus, it's crucial for policymakers to acknowledge people's behavioural responses to protect public health through adaptive measures. By developing a predictive model in this study, it is expected to help researchers and 


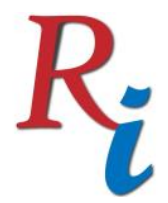

\section{Asia Proceedings of Social Sciences \\ (APSS) \\ www.readersinsight.net/APSS}

practitioners in environmental management to improve our understanding of community adaptive behavioural responses to air pollution.

\section{Methodology}

The face-to-face questionnaire survey was performed on a random sample of 450 individuals in Klang Valley. Klang Valley is an area that is suitable to signify urban air quality and how the community response towards the deterioration of air quality. The multi-stage cluster sampling technique was implemented for the reduction of large areas into smaller sections, phase by phase until the sampling units are reached. A set of the survey questionnaire was carefully designed from the previous environmental study (Kim, Jeong, \& Hwang, 2012; Koerth et al., 2013; Zhao, Cavusgil, \& Zhao, 2016), to ensure most of the issues concerning air pollution and community adaption towards the risk were included. Moreover, the results show that composite reliability values range between 0.632 and 0.946 and the variances extracted range between 0.513 and 0.746 , which meet the requirement of instrument's validity. For reliability, the Cronbach's Alpha value of all constructs is greater than 0.8 thus surpasses the suggested threshold of 0.7. The IBM SPSS Version 20.0 and SmartPLS was used to perform the required statistical analysis of the data from surveys.

\section{Results}

The standard deviation for each construct ranges from 0.924 to 1.025 . The mean value for the five constructs of the seven-point Likert scale was between 4.343 to 5.443. The urban community has been moderately concerned with adapting to the risk of air pollution. Several hypotheses for this study were supported. Perceived vulnerability $(\beta=0.246, \mathrm{t}=4.534$, $\mathrm{P}=0.000)$ and self-efficacy $(\beta=0.510, \mathrm{t}=9.653, \mathrm{P}=0.000)$ structures predicted adaptive behaviour. Increasing the perceived vulnerability and self-efficacy scores led to an increased score of adaptive behavioural responses. Collectively, the PMT variables explained $47 \%$ of the variance in adaptive behaviour on urban air pollution. 


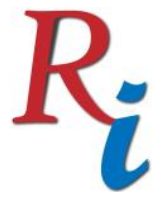

Asia Proceedings of Social Sciences

(APSS)

www.readersinsight.net/APSS

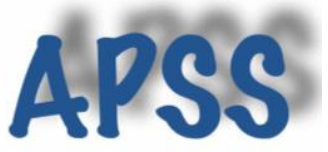

\section{Findings}

The specific goal of this study was to produce a trustworthy analysis of the adaptive behavioural reactions to urban air pollution based on four predictors (perceived vulnerability, perceived severity, self-efficacy and response efficacy) based on PMT. Based on findings from this study, it can be concluded that perceived vulnerability and self-efficacy thus predict the adaptive behavioural responses of the community in air pollution context. This study adds to a limited range of studies that have used the constructs of PMT to predict adaptive behaviour in an environmental context. When people face a threat especially on air pollution, PMT is considered a useful model to understand their behaviour towards the risk.

\section{Acknowledgement}

This research was funded by Research Management Centre (RMC), Universiti Putra Malaysia.

\section{References}

Ban, J., Zhou, L., Zhang, Y., Anderson, G. B., \& Li, T. (2017). The health policy implications of individual adaptive behavior responses to smog pollution in urban China. Environment International, $\quad$ 106(September 2016), 144-152. https://doi.org/10.1016/j.envint.2017.06.010

Giles, L. V., Brauer, M., Barn, P., Künzli, N., Romieu, I., Mittleman, M. A., ... Brauer, M. (2011). From good intentions to proven interventions: Effectiveness of actions to reduce the health impacts of air pollution. Environmental Health Perspectives, 119(1), 29-36. https://doi.org/10.1289/ehp.1002246

Kim, S., Jeong, S., \& Hwang, Y. (2012). Predictors of Pro- Environmental Behaviors of American and Korean Students : The Application of the Theory of Reasoned Action and Protection Motivation Theory. https://doi.org/10.1177/1075547012441692

Koerth, J., Jones, N., Vafeidis, A. T., Dimitrakopoulos, P. G., Melliou, A., Chatzidimitriou, E., \& Koukoulas, S. (2013). Household adaptation and intention to adapt to coastal flooding in the Axios - Loudias - Aliakmonas National Park, Greece. Ocean and Coastal Management, 82, 43-50. https://doi.org/10.1016/j.ocecoaman.2013.05.008

Laumbach, R., Meng, Q., \& Kipen, H. (2015). What can individuals do to reduce personal 


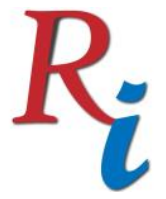

\section{Asia Proceedings of Social Sciences}

(APSS)

www.readersinsight.net/APSS

health risks from air pollution? Journal of Thoracic Disease, 7(1), 96-107. https://doi.org/10.3978/j.issn.2072-1439.2014.12.21

Rogers, R. W. (1975). A Protection Motivation Theory of Fear Appeals and Attitude Change1.

The Journal of Psychology, 91(1), 93-114. https://doi.org/10.1080/00223980.1975.9915803

Zhao, G., Cavusgil, E., \& Zhao, Y. (2016). A protection motivation explanation of base-ofpyramid consumers' environmental sustainability. Journal of Environmental Psychology, 45, 116-126. https://doi.org/10.1016/j.jenvp.2015.12.003

Author's Biography

Syazwani Sahrir obtained her Bachelor's Degree at International Islamic University Malaysia, majoring in Urban and Regional Planning. She then obtained her Master's Degree in Built Environment. Currently, she is a postgraduate student in the field of Environmental Management. Her research interest is in environmental management, urban planning, transport studies, and social impact assessment. 